85\%. Depression diagnosis increased from 21 children in 2015 to 34 in 2016, a $62 \%$ increase.

Conclusions Implementing behavioural health recommendations using PF led to increased screening, diagnosis and management of depression at an Appalachian primary care practice.

\section{A QUALITY IMPROVEMENT INITIATIVE REDUCES CAST COMPLICATIONS IN A PAEDIATRIC HOSPITAL}

Julie Samora, Walter Samora, Kevin Dolan, Kevin Klingele. Nationwide Children's Hospital, US

\subsection{6/bmjoq-2017-|HI.15}

Background Casts are frequently used as routine treatment in paediatric orthopaedic practice, and yet are not without complications. At our large tertiary care paediatric hospital, baseline rate of all casting complications was 5.6 complications per 1000 casts applied $(0.56 \%)$.

Objectives The project aimed to decrease the overall cast complication rate and improve patient care using quality improvement (QI) methodology.

Methods We implemented quality improvement concepts derived from the Institute for Healthcare Improvement (IHI) models, including Plan-Do-Study-Act (PDSA) cycles, to perform a quality improvement initiative to decrease our cast complication rate. We developed a resident casting education program with a competency 'checklist' to ensure that casts are applied, bivalved, and removed in a safe and standardised manner to prevent patient harm. We implemented a policy and procedure change, requiring AquaCast Saw Stop Protective Strips to be applied with every cast application. We reviewed our facility's processes and procedures and determined adequate measures were in place to effectively manage inventory and maintenance of cast saw blades.

Results With the multi-modal QI intervention, our complication rate was reduced to 0.15 complications per one thousand applications, a more than $90 \%$ improvement.

Conclusions Implementation of QI concepts to perform a quality improvement initiative resulted in a shift toward fewer cast complications, leading to overall improved patient care at a large tertiary paediatric hospital.

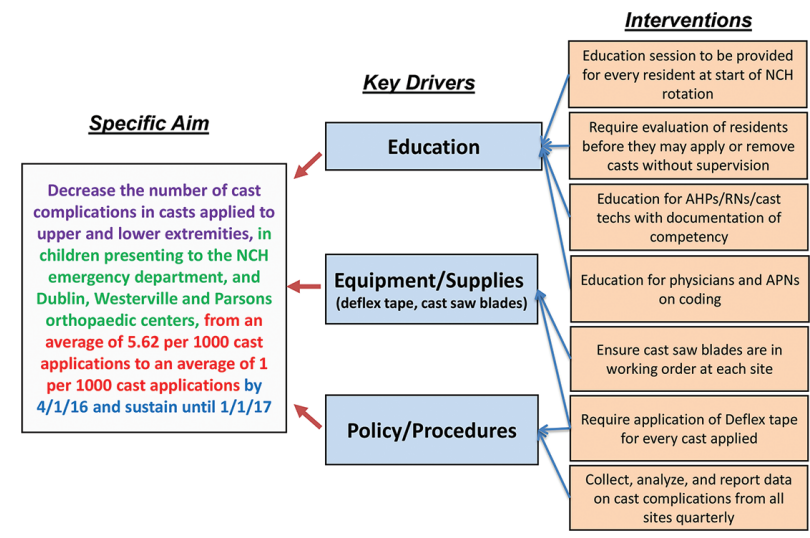

Abstract 935 Figure 1 Reduction of cast complications

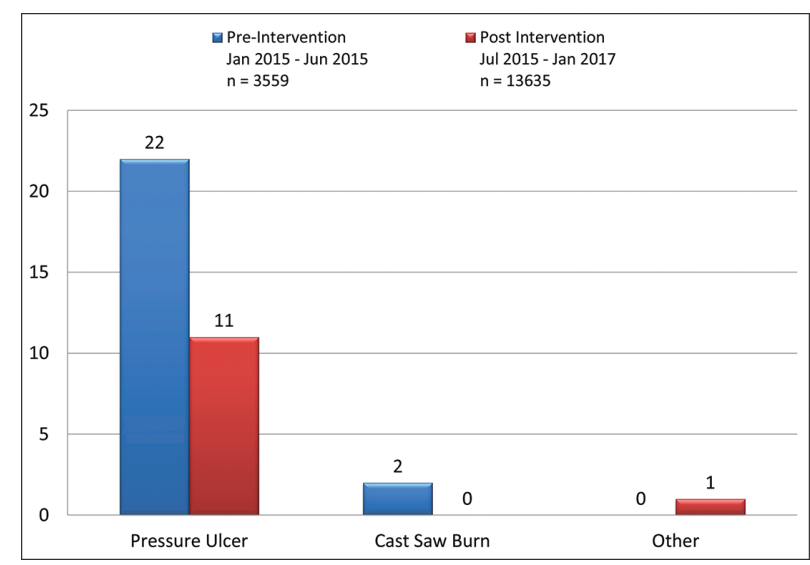

Abstract 935 Figure 3 Cast complications by category

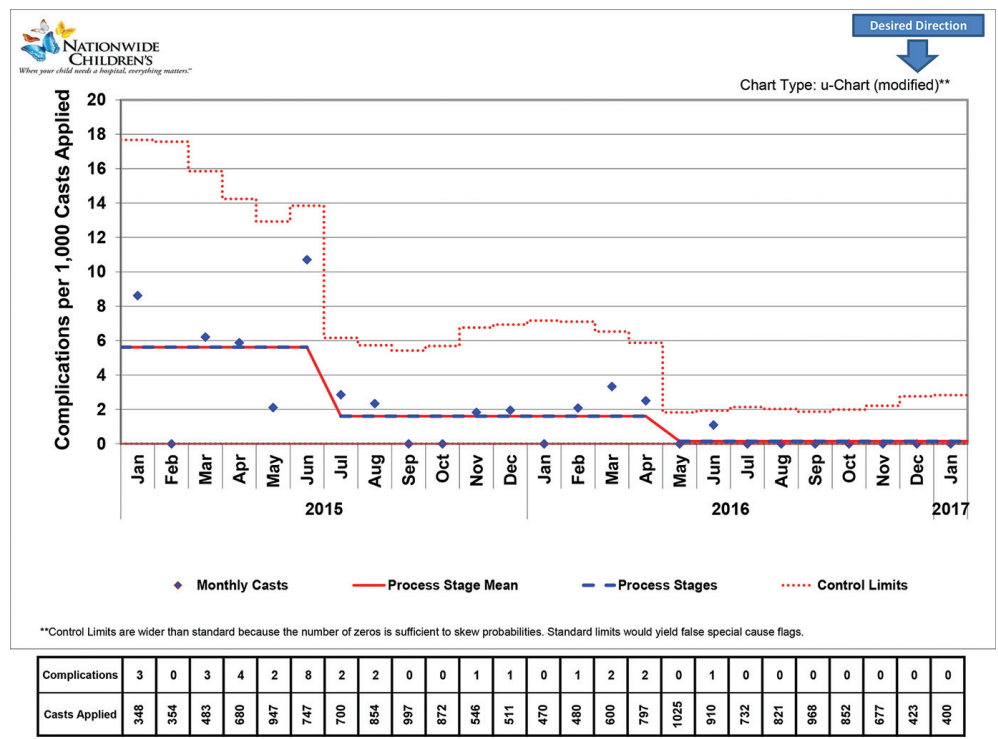

Abstract 935 Figure 2 Cast complications 